\title{
Tracking Change: Leisure Participation and Policy in Australia, 1985-2002
}

\author{
A. J. Veal \\ University of Technology, Sydney
}

[Published in Annals of Leisure Research, Vol. 6 No 3, 2003, pp. 245-277]

\begin{abstract}
This paper puts forward the proposition that the purpose of official national leisure participation surveys is: 1 . to track changes in overall leisure participation over time in order to evaluate policy aimed at promoting participation; and 2. to monitor variation in participation across social groups in order to evaluate policies directed at achieving equitable access to leisure opportunity. The chequered history of the various national leisure participation surveys conducted in Australia over the period 1985-2002 is examined to assess the extent to which they have achieved these goals. It is concluded that the fragmentation of government responsibility for leisure, the consequent failure to adopt a comprehensive approach to leisure and constant changes in survey design have prevented the first objective on overall participation from being achieved in any meaningful, consistent manner. Further, limited collection and publication of socio-economic data have prevented the second goal from being achieved. The paper concludes by calling for a consistent and comprehensive approach to leisure participation monitoring at the national level, as a basis for accountable policy and academic research.
\end{abstract}

\section{Background}

The recent publication of the results of two annual rounds of a major national survey, Participation in Exercise, Recreation and Sport, by the Australian Sports Commission (Dale and Ford, 2002; Standing Committee on Recreation and Sport, 2003), should be an event to be welcomed by leisure studies scholars and practitioners in Australia, since new, up-to-date information on a major part of our field of study is always welcome. But in fact the publication of these reports is a mixed blessing: they are the latest episodes in a long and sorry tale concerning the collection of data on leisure participation patterns in Australia.

A major concern of public policy in the field of leisure is the level of participation. In areas of leisure such as sport and the arts, arguably the main policy aim of governments is to stimulate, encourage and facilitate the maximum possible level of participation because of the social benefits which such participation is believed to produce. In addition to overall participation levels there is a concern for equity of access to leisure opportunities across all sections of the community. Even in sectors of leisure which involve natural areas, such as visiting national parks, where conservation values might preclude an all-out effort to maximise attendance, there is a concern that access should at least be equitable. Success in achieving equity of access should be reflected in reduced disparity in participation levels across different social groups over time. If public policy is concerned with levels of participation and equity in participation then it follows that, in order to monitor the success of such policy - to engage in 'evidence-based policy-making' (Leigh and Wolfers, 2003), data are required on levels of participation both for the community as a whole and among various groups in the community.

In other fields of public policy, such as health and education, data on levels and patterns of service usage are routinely collected at the point of delivery. But this is not the case with leisure participation, which involves a myriad of facilities managed by thousands 
of public, private and not-for-profit organisations, venues where attendance is not recorded (such as parks and beaches), and often no specific leisure facility at all (for example, leisure activities at home, or jogging in the street). So data on leisure participation must be collected by means of social surveys. This is widely recognised and practised by governments around the world (Cushman, Veal and Zuzanek, 1996). In particular, policy evaluation requires the collection of data on a comparable basis over time, so that the 'before and after' impact of policies on participation can be assessed.

At state and local government level, national survey data contribute to the policy process, sometimes providing state-level participation rates but also providing benchmark data for comparison and broad-brush demand estimates and, ideally, information on trends in participation (Veal, 2002: 122-7).

In addition to their main role as a policy tool, official participation data are also of use in academic work, in theoretical discussions and teaching, and in exploring such topics as equity, social change, gender issues, ageing, globalisation and commercialisation. Many of the academic requirements for such data sets are ostensibly similar to the policy requirements, including the use of valid methodology, appropriate sample sizes and consistency in scope and methodology over time.

In both leisure policy and theoretical leisure research - and indeed in theoretical research on leisure policy - the quantum of participation is, of course, not the only concern. Issues such as quality of experience are also highly relevant. But in the area of public policy, where public resources are used to support, facilitate and subsidise participation, numbers cannot be ignored. In the jargon of managerialism, they are 'key performance indicators'. Participation surveys are one way in which such indicators are established. This paper therefore concentrates on this very basis form of research on leisure. It is an aspect of leisure research which should be simple. The researcher and policy-maker should be able to take basic participation data for granted and move on to more complex and challenging issues. This paper demonstrates that this is far from the case in Australia.

The predecessor to Annals of Leisure Research published a review of the saga of leisure participation surveys in Australia up until the early 1990s (Veal, 1993a). The aim of this paper is to examine the extent to which national leisure participation surveys in Australia since the 1980s have fulfilled their public policy objectives and in particular to explore the proposition that inconsistency in methodology has undermine the policy utility of the many surveys which have been conducted. The next section of the paper considers the policy background in regard to leisure participation in Australia. Subsequent sections examine: the 'National Recreation Participation Surveys' (NRPS) of the 1980s; the Australian Bureau of Statistics surveys of sport and physical recreation conducted in the 1990s; the Australian Sports Commission's 2001 and 2002 'Exercise Recreation and Sport Survey' (ERASS); and other leisure-related surveys conducted from the 1980s to 2000.

\section{Leisure policy and participation in Australia}

It is not possible or appropriate to present a comprehensive analysis of leisure policy in Australia over the last two decade in this paper, but the following examples of policy statements are presented to illustrate the conceptual relationship between public policy and participation data both as evidence of the need for policy action and as indicators of the success or failure of policy measures.

In the 1980s when the policies of the Hawke Labor government were outlined in Towards a Commonwealth Policy for Recreation, published by the then Minister for Sport, Recreation and Tourism, John Brown. In the document the Minister declared that: 
The goal of the Government in recreation is to improve the quality of life of all Australians by encouraging and providing opportunities for greater participation in healthy and satisfying leisure time activities. (Brown, 1985: 11)

There is a tendency in many policy statements to use such non-directive terms as 'providing opportunities' and 'improving access', since 'Governments are not concerned with telling people how to spend their leisure time ..' (Brown, 1985: 8). However, if opportunities are provided and access improved but noone takes advantage of them, then the policy will surely be considered a failure. The ultimate test of the success of such policies is therefore increased participation - both overall and among targeted groups.

The link between policy and collection of data on participation was indicated in the government's 'first policy priority', which was 'data gathering':

It is now widely accepted that the development and implementation of effective government policies and programs must be based on accurate information about current conditions in the community. .. While it is not intended that the department [of Sport, Recreation and Tourism] should have a major research function, the Department is examining a range of options for its involvement in this area, including ... commissioning of regular national surveys of recreation participation patterns ... a first priority must be the creation of a comprehensive data base covering what Australians are doing in their leisure time ... The Government will be working towards this end through the conduct of regular national recreation participation and attitudinal surveys which will take account of seasonal variations in recreation participation patterns and will provide a longitudinal perspective on recreation. (Brown, 1985: 15, 26)

The second policy priority was information dissemination and the third was 'equitable provision of recreation'. In regard to the latter the Minister stated:

Available evidence suggests that many Australians are not participating in satisfying recreational experiences. If opportunity to participate in recreation is affected by environmental factors, the provision of more equal opportunity cannot be achieved simply by treating everyone alike. It involves action which will supplement the opportunities available to those sections of the community whose attitudes and general life conditions are least conducive to their participation in enjoyable leisure time pursuits. In a context of finite resources, those who have been disadvantaged in terms of access to recreation require a greater share of available support and resources. (Brown, 1985: 28)

The policy document went on to identify a number of potentially disadvantaged groups, including: people living in rural areas or newly developed housing estates; women with below school-age children; people with English language difficulties; people who may lack confidence or status, including women and the unemployed; those on low incomes; teenagers; the aged; and people with disabilities.

While John Brown's ministerial portfolio did not include the arts or the environment, it did include 'recreation' and it is notable that policies were related to the broadly defined area of leisure. This broad scope was reinforced later, when the remit of the ministerial and corresponding departmental portfolio was widened from 'Sport, Recreation and Tourism' to 'The Arts, Sport, the Environment, Tourism and Territories' (DASETT). 
The conservative Howard Liberal-National Coalition government, which came to power in 1996, put forward policies which, while more cautious and limited in scope than those of its predecessor, nevertheless expressed sentiments which were not dissimilar. Thus the Coalition's 1998 policy document, A Winning Edge, said: 'By working with the Health and Education portfolios to develop the Active Australia programme, the Howard Government has vigorously encouraged participation in sport for all' (Liberal/National Coalition, 1998). In recognition of equity issues, it went on to draw attention to programs aimed at 'older Australians', women and Aboriginals and Torres Strait Islanders. In the 2001 policy document, Backing Australia's Sporting Ability, the government stated:

Together we will aim to: significantly increase the number of people participating in sport right across Australia, including rural and regional communities; and markedly increase youth participation in organised sport ... (Commonwealth of Australia, 2001: 5)

While concerned with participation and equity, the Coalition government limited policy to the more limited area of sport, rather than recreation or leisure.

Government statements about participation and equity are also made in relation to the specific area of the arts, although in this context 'participation' or 'access', is generally concerned with the public's role as audiences at performances or as visitors to a museums or galleries, rather than as active participants in production of the arts. Thus the 1994 Labor government's Creative Nation policy document stated that one of the roles of government was to enable ' ... all Australians to enjoy the widest possible range of cultural experience' and that the pursuit of 'the twin goals of democracy and excellence. ... will make the arts and our intellectual and cultural life and heritage more accessible to all' (Commonwealth of Australia, 1994: 12, 5). On equity issues, the document outlined policies directed at youth, at regional Australia through funding support for touring, and at regional and Aboriginal Australia via support for broadcasting services.

The Liberal-National Coalition's 2001 election policy statement Arts for All, stated: 'Our aim is to encourage excellence in, and access to, all areas of the arts in Australia, and to encourage all Australians to celebrate our culture and creativity'. (Liberal-National Party Coalition, 2001: 3). On equity, it stated:

Artists and audiences in rural and regional Australia want to participate in, and experience, the arts as much as those living in metropolitan and urban areas. Accordingly, the Coalition has focussed on increasing access to our National Cultural Institutions through improved online access, and an increase in the number of exhibitions and performances travelling to rural and regional Australia. (LiberalNational Party Coalition, 2001: 3)

It is notable, however, that in sections of the document on 'Highlights of the Government's Achievements' and 'Labor's Record', all items refer to 'supply side' or 'inputs' aspects of programs - no evidence is presented on 'outcomes - that is on the extent to which arts participation has increased.

While the above examples of government policy statements refer to the federal government, in practice much leisure policy is implemented by state, territory and local governments, most of which also have policy objectives related to leisure participation and equity. For example, under the slogan 'More people, more active, more often' the New South Wales Department of Sport and Recreation Corporate Plan 2003-2007 (NSW Dept. 
of Sport and Recreation, 2003a) seeks the following 'outcome': 'People in NSW regularly engage in and benefit from safe and enjoyable sport, recreation and physical activity'. The related 'corporate measurement and target' is: 'An additional 50,000 people per year involved in physical activity'. ${ }^{1}$

\section{The 1980s: National Recreation Participation Surveys}

The surveys

As a direct result of the 1985 ministerial policy statement quoted above, the Department of Sport, Recreation and Tourism and later the Department of the Arts, Sport, the Environment, Tourism and Territories, commissioned survey company AGB:McNair to conduct the National Recreation Participation Survey (NRPS) on six occasions from 1985 to 1991. Details are provided in Table 1. While based on a modest sample of some 2500 interviews, which did not permit detailed analysis, for example by state or by individual low-participation activities, the surveys had the merit of covering all aspects of leisure, including participation in home-based activities, formal and informal sport, informal outdoor recreation, and social activities, entertainment and the arts, reflecting the wide terms of reference of the DRST and DASETT portfolios.

Table 1. National Recreation Participation Surveys, Australia, 1985-91

\begin{tabular}{lllllll}
\hline Year: & 1985 & 1985 & 1986 & 1986 & 1987 & 1991 \\
\hline Season & Winter & Spring & Summer & Autumn & Spring & Summer \\
\hline Organisation & DSRT & DSRT & DSRT & DSRT & DASETT & DSRT \\
\hline Sample size & 2500 & 2500 & 2500 & 2500 & 2068 & 2103 \\
\hline Age-range & $14+$ & $14+$ & $14+$ & $14+$ & $14+$ & $14+$ \\
\hline Area covered & Nationwide & Nationwide & Nationwide & Nationwide & Nationwide & Nationwide \\
\hline $\begin{array}{l}\text { Activities } \\
\text { covered }\end{array}$ & All leisure* & All leisure* & All leisure* & All leisure* & All leisure* & All leisure* \\
\hline $\begin{array}{l}\text { Reference } \\
\text { period }\end{array}$ & 1 week & 1 week & 1 week & 1 week & 1 week & $\begin{array}{l}\text { 1week + 1 } \\
\text { month }\end{array}$ \\
\hline $\begin{array}{l}\text { Participation } \\
\text { measure }\end{array}$ & At least once & At least once & At least once & At least once & At least once & At least once \\
\hline $\begin{array}{l}\text { Equity variables } \\
\text { References }\end{array}$ & Age, gender & Age, gender & Age, gender & Age, gender & Age, gender & Age, gender \\
\hline
\end{tabular}

* 90 activities, including home-based, sport, arts, informal recreation, organised and non-organised

\section{Trends in participation}

The basic participation question asked in the surveys used a 'reference period' of just one week $^{2}$ and the surveys were conducted seasonally, so the participation rates were seasonspecific and only surveys from the same season could safely be compared to assess trends in participation (Veal 1993b). Between 1985 and 1991 two summer, two spring, one autumn and one winter NRPS surveys were conducted, so changing patterns of participation could only be assessed between the two summer surveys and between the two spring surveys. Given the many factors likely to influence leisure participation, just two comparable 'points on the graph' are not an adequate basis upon which to establish trends in participation and to evaluate policy. But the NRPS was abandoned in 1991, before additional comparable surveys had been conducted and so it was not able to provide the 'longitudinal perspective 
on recreation' which had been the aim declared in the 1985 ministerial statement, and none of the officially published reports attempted to plot and evaluate trends over time by reference to previous surveys.

Equity

As regards equity, only two variables were presented in the NRPS published reports: age and gender. Many other variables were available from the ACB:McNair omnibus survey, including occupation/socio-economic group, education level, household size and structure, country of birth and income. In a volume of essays from invited academics, using printouts of tables from the first NRPS made available by the department, papers on education (Rogers 1989) and occupation (Auld 1989) were included, but no subsequent departmental reports made reference to variables other than age and gender. Later, tables showing the relationship between participation and occupation were published based on secondary analysis of the data conducted by academics (Darcy and Veal, 1996; Lynch and Veal, 1996: 130-31; Veal and Lynch, 2001: 154-55), but there was no published evidence of equity data informing public policy.

\section{Surveys in the 1990s: a new regime}

In the early 1990s, the joint federal and state Sport and Recreation Ministers Council began an initiative to establish a 'Sport and Recreation Industry Statistical Framework' and consider the question of on-going collection of associated data. This parallelled similar work being undertaken by ministers and departments of culture in relation to a 'leisure and culture' statistical framework. The draft report outlining the sport and recreation framework listed just fourteen 'organised sports', ten 'active recreation' activities, three 'amusements and passive recreation' and three gambling activities (Corporate Concern 1994a) ${ }^{3}$.

In place of the NRPS there emerged a new annual survey, conducted by the Australian Bureau of Statistics (ABS) using its annual 'Population Survey Monitor' (PSM), an omnibus survey with much larger samples than the NRPS. Despite the involvement of ministers and departs of the arts and culture in considering 'leisure and culture', the main 'clients' for the new survey were the federal and state departments and ministers of recreation and sport only. The results from the 1993-94 and 1994-95 surveys were not formally published by ABS, but were made available to the federal and state departmental clients. A draft report by consultants Corporate Concern (1994b) contained some of the results, reflecting the limited lists of activities indicated above. From 1995-96, however, ABS began publishing annual reports of the PSM survey results including participation in 42 separate sporting activities $^{3}$. Details of the surveys are provided in Table 2 .

Three major changes in survey methodology were instituted in the PSM, which made comparisons with the 1985-91 NRPS results impossible, so that trends from the 1980s could not be examined. These changes related to: a. the narrowing of the range of activities included; b. the question of 'organised' versus 'social' participation; and c. the activity 'reference period'.

\section{a. Narrowing the range of activities}

The PSM covered 'sport and physical activities' only. No explanation for this narrowing of activity focus was given in the published report, but it can be surmised that the explanation was to do with the terms of reference of ministerial portfolios. The federal minister's 
Table 2. National sport and physical activities surveys, Australia, 1995-2002

\begin{tabular}{|c|c|c|c|c|c|c|c|c|c|c|c|}
\hline $\begin{array}{l}\text { Year of } \\
\text { survey }\end{array}$ & $\begin{array}{l}\text { Organis- } \\
\text { ation }\end{array}$ & $\begin{array}{l}\text { Survey } \\
\text { vehicle }\end{array}$ & $\begin{array}{l}\text { Age- } \\
\text { range }\end{array}$ & Sample size & $\begin{array}{l}\text { Reference } \\
\text { period }\end{array}$ & $\begin{array}{l}\text { Organised } \\
\text { activities }\end{array}$ & $\begin{array}{l}\text { Non- } \\
\text { organised } \\
\text { activities }\end{array}$ & $\begin{array}{l}\text { Organised } \\
\text { activities } \\
\%\end{array}$ & $\begin{array}{l}\text { Non- } \\
\text { organised } \\
\text { activities \% }\end{array}$ & Equity variables & References \\
\hline 1995-96 & ABS & PSM & $15+$ & 22,000 & Year & Yes & Not & 30.7 & - & \multirow{5}{*}{$\begin{array}{l}\text { age; gender; capital } \\
\text { cities vs regions; } \\
\text { country of birth; } \\
\text { employment status }\end{array}$} & ABS, 1997a \\
\hline 1996-97 & $"$ & $"$ & $18+$ & 26,000 & $"$ & " & Not & 26.5 & - & & ABS, 1998a \\
\hline $1997-98$ & $"$ & $"$ & " & 12,500 & $"$ & " & Yes* & 28.3 & $47.8^{*}$ & & ABS, $1998 b$ \\
\hline 1998-99 & " & $"$ & " & 13,000 & $"$ & $"$ & Yes & 30.3 & 59.4 & & ABS, 1999 \\
\hline 1999-00 & $"$ & $"$ & $"$ & 13,000 & $"$ & " & Yes & 28.9 & 54.7 & & ABS, 2000 \\
\hline 2000-01 & $\mathrm{ASCl}$ & ERASS & $15+$ & 13.6 & $"$ & $"$ & Yes & 39.9 & 77.8 & \multirow{2}{*}{$\begin{array}{l}\text { as above }+ \text { marital } \\
\text { status, education, \& } \\
\# \text { children aged }<8 \text { yrs }\end{array}$} & $\begin{array}{l}\text { Dale \& Ford } \\
2002\end{array}$ \\
\hline 2001-02 & $\begin{array}{l}\text { SCORS* } \\
*\end{array}$ & $"$ & $"$ & 13.6 & $"$ & $"$ & Yes & 40.9 & 77.8 & & $\begin{array}{l}\text { SCORS**, } \\
2003\end{array}$ \\
\hline
\end{tabular}

PSM = Population Survey Monitor. ERASS - Exercise, Recreation and Sport Survey. * Excludes unorganised walking and ** SCORS = Standing Committee on Recreation and Sport. $\dagger$ Data were also collected on 'social sport and physical activities in 1995-6 and 1996-7, but for a reduced sample of respondents aged 18+ only, for the two weeks prior to interview (in August, November, February and May), but data on only 13 'selected' activities were published. 
portfolio no longer included the arts or the environment, and the state ministers involved had similarly limited 'sport and recreation' portfolios. Demarcation in relation to the portfolios of the culture ministers and departments, meant that the arts and entertainment were dealt with separately (see below). 'Environmental' activities, such as visiting national parks and beaches, are generally the responsibility of environmental ministers, but no national data have been regularly collected on such activities in recent years. Home-based leisure activity was never part of any ministerial portfolio, although data had been included in the NRPS and were subsequently collected in the ABS Time-Use surveys (see below). Thus fragmentation of ministerial responsibilities resulted in fragmentation of data collection. The ways in which data participation in a number of these non-sport areas of leisure have been subsequently pursued in Australia are examined briefly in the penultimate section of the paper.

\section{b. Organised versus social activity}

A further narrowing of the range of activity resulted from the main focus of the survey being on participation in organised sport only - that is participation with a club or other organisation. Questions on 'social participation' in sporting activities - that is, any participation not engaged in under the auspices of a club or other organisation - were included, but only for a reference period of two weeks, so the results could not be combined with the 'organised' data to produce an overall annual participation rate, and social participation results were reported for only 13 activities. By contrast the NRPS had gathered information on organised and social participation for all activities on a comparable basis.

\section{c. Reference period}

The second major change instituted in the PSM was in the 'reference period' over which respondents were asked to indicate their participation, which was increased from the one week used in NRPS to a year. One effect of the change to a longer reference period was to greatly increase the size of the participation figures, since, for many activities, more people engage in activities once or twice a year than do so on a frequent or regular basis. While one year reference periods are increasingly common in leisure participation surveys, the wisdom of using such a long reference period is questionable. While a one-year reference period overcomes the problem of seasonality in the data, there is some doubt as to the accuracy of respondents' recall over such a long period and the effect of this on reported participation rates. The tendency for respondents to exaggerate levels of participation in 'approved' activities and perhaps under-report participation in others has been established (see Chase and Godbey, 1983; Chase and Harada, 1984; Bachman and O'Malley, 1981). A long reference period seems likely to exacerbate this 'rose-coloured spectacles' tendency. There may, on the other hand, be an 'absent-mindedness' tendency - for respondents to forget irregular or one-off participation events - resulting in under-reporting of participation. Further, while participation 'at least once a year' might be a useful, although limited, measure for some types of leisure activity, such as visiting a theatre, a museum or a zoo, it hardly seems appropriate for sport and physical activity, since it is regular participation in such activities which brings benefits.

Despite the design changes, since the ABS survey was conducted on a much larger scale than the NRPS and was sponsored by state governments as well as the federal government, hopes of a long-term data-set, at least relating to sport, were high. The results in relation to overall participation levels are shown in Table 3 and Figure 1, together with results from later surveys discussed below. The data for the last, Summer 1991, NRPS are also shown. Despite the more restrictive one week reference period of the NRPS, it 
indicates a considerably higher level of participation. The high reported participation level for 'organised' participation suggests the use of a different definition, although comparison of the NRPS and later ERASS survey questionnaires reveals no obvious difference. The fact that the NRPS survey was undertaken in summer, when participation in sporting activities is at its highest, lends support to the idea that the longer reference period of a year used in the other surveys results in 'absent-mindedness' and under-reporting of participation.

Table 3. Organised and non-organised sport participation, Australia, 1995-2002

\begin{tabular}{lccc}
\hline Survey & Organised $\%$ & $\begin{array}{c}\text { Non-organised } \\
\text { only } \%\end{array}$ & All \% \\
\hline NRPS, 1991 & 75.0 & 6.9 & 81.9 \\
ABS/PSM 1995-96 & 30.7 & - & - \\
ABS/PSM 1996-97 & 26.5 & - & - \\
ABS/PSM 1997-98 & 28.3 & 19.5 & $47.8 *$ \\
ABS/PSM 1998-99 & 30.3 & 29.1 & 59.4 \\
ABS/PSM 1999-00 & 28.9 & 24.9 & 54.7 \\
ERASS 2000-01 & 39.9 & 37.9 & 77.8 \\
ERASS 2001-02 & 40.9 & 36.9 & 77.8 \\
\hline
\end{tabular}

\section{5-96 to 1996-97: Organised Sport}

For the two years 1995-96 and 1996-97, the survey design remained unchanged, notably showing an apparent decline in participation in organised sport between 1995-6 and 1996-7, as shown in Table 3 and Figure 1. The overall level of participation was a modest 31\%, falling to $27 \%$ in 1996-97. This was probably disappointing for the ministers and departments of sport and recreation. By contrast, although overall sport participation was not emphasised in the NRPS reports, the last, summer 1991, survey had recorded $77 \%$ participation in organised sport and $75 \%$ participation in informal sport. ${ }^{5}$ Given that the reference period had been increased to one year, the expectation would be that the new survey vehicle would produce a higher participation rate than the NRPS, not a lower one. This may indicate that the 'absent-mindedness' tendency, as discussed above, was at work.

Equity variables presented in these and subsequent ABS published reports were: age; gender; capital cities versus other areas; country of birth; and employment status. The substantial sample sizes meant that state-specific participation rates could also be presented. The issue of equity is examined in relation to the series of surveys from 1995-96 to 2001-02 following the general discussion of the series.

\section{Participation 1997-98: Bringing in the Social}

Following just two years of stability, in 1997-8 the survey design was changed, although no rationale for this was given in the published report. The major change was that the basic data item on participation was extended to include 'social' as well as 'organised' participation: this would be expected to increase overall reported participation rates. There are, of course, good reasons for including 'social', or 'informal', participation in sport participation figures, despite the difficulties of definition for some activities. While most government funding goes to organised sport, for certain popular activities, such as walking, swimming, jogging and cycling, the bulk of activity is non-organised. Arguably, the sum of 
'unorganised' sport makes a greater contribution to the nation's health and leisure enjoyment than the sum of 'organised' sport.

Definitional problems arise first in relation to intrinsically informal activities, such as visiting a park or beach: at what point should these activities be classified as 'walking' or 'swimming'? Second, there are issues regarding highly informal sport participation: for example, at what point should 'kicking a ball around' be classified as 'playing football'? In both cases, the decision is left to the survey respondent, raising questions as to the effect of varying respondent assessment.

Two further changes were made in the 1997-98 survey. The age-range of the sample was changed from 15+ to those aged 18+ only, which would be expected to reduce overall participation rates because 15-17 year-olds can be expected to be more active than the average adult. And the sample size was halved, which was unlikely to affect reported participation rates, but would affect the ability to report on activities with very low participation rates.

As Table 3 and Figure 1 indicate, while the 1997-98 organised sport participation rate remained below $30 \%$, the addition of non-organised participation meant that a higher overall sport participation rate, of $48 \%$, was reported. This was clearly a more satisfactory 'headline' figure for Ministers and departments charged with a mandate to achieve high levels of participation.

\section{8-99 and 1999-2000: Running, Walking and Standing Still}

If users of the data thought that stability would now be established, they were mistaken. The 1998-99 report drew attention to the fact that, in the previous year, despite the inclusion of non-organised participation generally, 'participation in running/jogging and walking that was not organised by a club or association was excluded' (ABS, 1999a: 25). This was now changed, resulting in the recorded participation in running increasing from $0.4 \%$ to $4.8 \%$ and in walking from $1.3 \%$ to $22.7 \%$. Due in part to these changes, reported participation in all sport and physical recreation increased from $48 \%$ to $59 \%$. Thus the 'headline' figure of 'sport participation' was now almost $60 \%$ of the population.

No changes were announced in the 1999-2000 survey, so once again there were two comparable 'points on the graph', 1998-99 and 1999-2000, indicating small declines in both organised and overall participation.

\section{Summing up the 1990s}

The series of ABS/PSM reports were therefore subject to a series of changes, the rationales for which were not explained in the published reports. A later paper from ABS indicated only that they had been due to 'Changing user requirements and ABS procedures' (ABS, 2002: 7). The result was that, while trends in overall participation rates could not be examined, trends in participation in organised activity could be examined. As shown in Table 3 and Figure 1, however, even leaving aside the difference between the NRPS and the ABS survey results, there was not a great deal to show for half a decade of government promotion and subsidy: the organised participation rate in 1999-2000 was marginally lower than that in 1995-96.

\section{The new millennium}

The new vehicle

Come the new century, and the federal and state departments deserted the ABS and took their custom to the Australian Sports Commission and 'ERASS' - the Exercise, Recreation 
and Sport Survey. ${ }^{6}$ Needless to say, although there were many similarities with the ABS surveys of the 1990s, once again the opportunity was taken to introduce changes in the design. In particular the data collection methodology was changed from face-to-face interviews to telephone interviews (the effects of which on reporting of participation is debatable), and the age-range of the sample was again changed from $18+$ back to $15+$. Young people aged 15-17 years are probably the most active participants in the range of activities included in 'exercise, recreation and sport', so the inclusion of this group could be expected to have an impact on overall reported participation rates.

The timing of this change of survey vehicle is significant. Interviews for the first ERASS were carried out in February, May, August and November 2001, so the 'year prior to interview' to which reported participation related covered the period March 2000 to November 2001. What is notable about this particular period is that it covered the period of immediate build-up to, and aftermath of, the September 2000 Sydney Olympic Games, when consistent measurement of any changing levels of sport participation in the community would have been particularly useful. This is particularly so since one of the arguments for investing public resources in major sporting events is to boost grassroots participation (Houlihan, 1997: 71). However, the changes in survey vehicle and methodology immediately raise doubts as to whether any recorded changes were 'real' or were due to these methodological changes.

\section{An increase in participation?}

The change in survey vehicle produced an overall participation rate of $78 \%$ in 2000-2001, and exactly the same figure in the following 2001-02 survey (see Table 3 and Figure 1). The 'headline' rate of participation in sport and physical activities was now more than $20 \%$ higher than the figure produced from the ABS 1999-2000 survey.

Was this dramatic increase due to a real boom in participation or to the inclusion of 15 17 year-olds in the sample? The age-related tables in the ERASS report do not provide a clear answer since the 15-17 year-olds were not separated out, but were included in the 1524 year-old age-group (Dale and Ford, 2001: 5, 10). Nevertheless, if the 15-17 year-olds were responsible for the increase, it might be expected that the participation rate for the youngest age-group would show a much higher than average increase. But this was not the case. As shown in Table 4, while the overall participation rate was $23 \%$ higher in the ERASS compare with ABS/PSM, the increase for the youngest age-group was only $15 \%$. The biggest differences in participation rates were among the older age-groups.

An alternative hypothesis is that the Olympic Games indeed had an impact, with increases in participation in Olympic sports providing a real boost to overall participation levels. Table 5 presents an analysis of changes in reported participation rates between the two surveys, comparing Olympic and non-Olympic sports. The picture presented is a very mixed one. While a number of Olympic sports show significant apparent increases in participation, a number show little if any, and three show a decline. It is notable that, because of the low starting point, quite small absolute increases in participation for some sports can be proportionately very large - for example, an increase in athletics participation, from $0.1 \%$ to $0.7 \%$ is $600 \%$ increase. But the overall pattern is similar for non-Olympic activities, with walking ${ }^{7}$ and bush-walking showing the largest increases of any activities, at $10 \%$ and 5\% respectively (the latter was not included in the 1999-2000 survey). The aggregate of the percentage increases for the Olympic sports is 18.0, while for non-Olympic sports it is 20.6. A further issue is whether any increase is sustained over time. It can be 
Table 4. Sport and physical activity by age-group, Australia, 1999-2000 and 2000-2001

\begin{tabular}{l|ccc|c}
\hline Age-group & $\begin{array}{c}\text { ABS/PSM } \\
1999-00\end{array}$ & $\begin{array}{c}\text { ERASS } \\
\text { 2000-01 }\end{array}$ & $\begin{array}{c}\text { Difference, } \\
1999-00 \text { to } \\
2000-01\end{array}$ & $\begin{array}{c}\text { ERASS } \\
2001-2002\end{array}$ \\
\hline & \% participating in previous year & $\%$ & $\begin{array}{c}\text { \% participating in } \\
\text { previous year }\end{array}$ \\
\hline 18-24 (ABS/PSM)/ & 73.5 & 88.8 & 15.3 & 89.5 \\
15-24 (ERASS) & & & & \\
$25-34$ & 66.6 & 85.3 & 18.7 & 83.3 \\
$35-44$ & 58.1 & 80.6 & 22.5 & 78.9 \\
$45-54$ & 48.5 & 75.4 & 26.9 & 76.3 \\
$55-64$ & 43.2 & 70.2 & 27 & 71.7 \\
65 \& over & 33.8 & 60.1 & 26.3 & 62.1 \\
Total & 54.7 & 77.8 & 23.1 & 77.8 \\
\hline
\end{tabular}

Sources: ABS (2000: 6); Dale and Ford (2002: 5)

assumed that the changes from 2000-01 to 2001-02 shown in Table 5 are 'real, since the survey methods for the two years were unchanged. While seven Olympic sports showed a further increase in participation, nine showed a decline in participation - which, ironically, could be an indicator of an 'Olympic effect', since one possibility is that such an effect would be, at least partially, short-lived. But again, comparison with non-Olympic sports shows a similar pattern of small rises and declines.

Given this mixed picture, if the overall participation increase in 2000-01 was 'real', rather than due to the change in survey vehicle, it is difficult to attribute it to the Olympic Games. It might be argued that the Games could inspire participation in sport generally, not just Olympic sports, but this is difficult to reconcile with the fact that the biggest apparent increase in participation was in non-competitive walking. It is also notable that certain popular activities, including lawn bowls, golf, ten-pin bowling and fishing, experienced significant declines in participation, which might indicate at best a shift from one activity to another and, at worst, a 'couch potato' syndrome induced by so much sport coverage on television.

The real reason for the apparent increase in participation between 1999-2000 and 20002001 therefore remains a mystery. If there had been no change in survey vehicle at least one source of mystery would not be present and a policy outcome could have been accurately measured.

\section{Equity outcomes - 1995-2002}

Analysis of the survey evidence equity outcomes in sport and physical activity participation between 1995 and 2002 would merit a paper in its own right. For the ABS/PSM surveys there was some consistency in the inclusion of six equity variables in every published report. These were: state of residence; capital cities vs regions; age; gender; country of birth; and economic status. The exception to the rule was the omission of country of birth from the 1996-97 report. 
Table 5. Sport participation, 1999-00, 2000-01, 2001-02, Australia

\begin{tabular}{|c|c|c|c|c|c|c|}
\hline \multirow{3}{*}{ Activities } & \multirow{3}{*}{$\begin{array}{l}\text { ABS/PSM } \\
\text { 1999-00 } \\
\% \text { particip }\end{array}$} & \multirow{3}{*}{$\begin{array}{c}\text { ERASS } \\
\text { 2000-01 } \\
\text { ating in year }\end{array}$} & \multirow{2}{*}{\multicolumn{2}{|c|}{$\begin{array}{l}\text { Change, } \\
1999-00 \text { to2000-01 }\end{array}$}} & \multicolumn{2}{|c|}{ ERASS 2001-02 } \\
\hline & & & & & \multirow{2}{*}{$\begin{array}{l}\% \text { partic- } \\
\text { ipating in } \\
\text { year }\end{array}$} & \multirow{2}{*}{$\begin{array}{c}\text { Change, } \\
2000-01 \text { to } \\
2001-02 \\
\end{array}$} \\
\hline & & & $\%$ & Prop. & & \\
\hline \multicolumn{7}{|l|}{ Olympic sports } \\
\hline Cycling & 4.9 & 9.5 & +4.6 & +93.9 & 9.3 & -0.2 \\
\hline Running & 4.7 & 7.2 & +2.5 & +53.2 & 7.6 & +0.4 \\
\hline Soccer (outdoor) & 1.4 & 3.7 & +2.3 & +164.3 & 4.5 & +0.8 \\
\hline Swimming & 13.9 & 16.0 & +2.1 & +15.1 & 14.9 & -1.1 \\
\hline Tennis & 7.4 & 9.2 & +1.8 & +24.3 & 8.2 & -1.0 \\
\hline Weight-training & 1.3 & 2.9 & +1.6 & +123.1 & 2.2 & -0.7 \\
\hline Basketball & 2.3 & 3.5 & +1.2 & +52.2 & 4.0 & +0.5 \\
\hline Athletics/track \& field & 0.1 & 0.7 & +0.6 & +600.0 & 0.7 & - \\
\hline Volleyball & 1.1 & 1.7 & +0.6 & +54.5 & 1.9 & +0.2 \\
\hline Softball & 0.3 & 0.8 & +0.5 & +166.7 & 0.7 & -0.1 \\
\hline Hockey (outdoor) & 0.5 & 1.0 & +0.5 & +100.0 & 0.9 & -0.1 \\
\hline Rowing & 0.2 & 0.4 & +0.2 & +100.0 & 0.4 & - \\
\hline Baseball & 0.1 & 0.3 & +0.2 & +200.0 & 0.3 & - \\
\hline Boxing & 0.3 & 0.4 & +0.1 & +33.3 & 0.3 & -0.1 \\
\hline Gymnastics & 0.3 & 0.4 & +0.1 & +33.3 & 0.3 & - \\
\hline Canoeing/kayaking & 0.7 & 0.7 & - & - & 0.7 & - \\
\hline Triathlon & 0.2 & 0.2 & - & - & 0.4 & +0.2 \\
\hline Badminton & 0.6 & 0.6 & - & - & 0.7 & +0.1 \\
\hline Sailing & 1.0 & 1.0 & - & - & 0.9 & -0.1 \\
\hline Martial arts & 2.2 & 2.1 & -0.1 & -4.5 & 2.1 & - \\
\hline Horse riding & 1.6 & 1.5 & -0.1 & -6.3 & 1.2 & -0.3 \\
\hline Table tennis & 1.2 & 0.5 & -0.7 & -58.3 & 0.6 & +0.1 \\
\hline \multicolumn{7}{|c|}{ Non-Olympic sports/physical activities } \\
\hline Walking (other) & 18.8 & 28.8 & +10.0 & +53.2 & 30.8 & +2.0 \\
\hline Walking (bush) & - & 5.3 & +5.3 & +100.0 & 5.6 & +0.3 \\
\hline Aerobics/fitness & 10.5 & 13.0 & +2.5 & +23.8 & 14.6 & +1.6 \\
\hline Yoga & - & 1.5 & +1.5 & +100.0 & 3.0 & +1.5 \\
\hline Netball & 2.7 & 4.1 & +1.4 & +51.9 & 4.1 & - \\
\hline Touch football & 1.4 & 2.7 & +1.3 & +92.9 & 2.4 & -0.3 \\
\hline Dancing & 0.9 & 2.0 & +1.1 & +122.2 & 2.1 & +0.1 \\
\hline Aust. Rules football & 1.4 & 2.3 & +0.9 & +64.3 & 2.5 & +0.2 \\
\hline Cricket (outdoor) & 1.9 & 2.7 & +0.8 & +42.1 & 3.0 & +0.3 \\
\hline Soccer (indoor) & 0.4 & 1.2 & +0.8 & +200.0 & 1.9 & +0.7 \\
\hline Motor sports & 0.5 & 1.0 & +0.5 & +100.0 & 0.9 & -0.1 \\
\hline Roller sports & 0.4 & 0.9 & +0.5 & +125.0 & 0.8 & -0.1 \\
\hline Cricket (indoor) & 0.8 & 1.3 & +0.5 & +62.5 & 1.2 & -0.1 \\
\hline Rugby league & 0.7 & 1.1 & +0.4 & +57.1 & 1.0 & -0.1 \\
\hline Rock climbing & 0.4 & 0.8 & +0.4 & +100.0 & 0.8 & - \\
\hline Rugby union & 0.3 & 0.6 & +0.3 & +100.0 & 0.7 & +0.1 \\
\hline Surf sports & 2.1 & 2.4 & +0.3 & +14.3 & 2.2 & -0.2 \\
\hline Squash/racquetball & 2.0 & 2.2 & +0.2 & +10.0 & 2.3 & +0.1 \\
\hline Aquarobics & 0.7 & 0.9 & +0.2 & +28.6 & 0.9 & - \\
\hline Hockey (indoor) & - & 0.2 & +0.2 & +100.0 & 0.2 & - \\
\hline Waterski/power boating & 1.1 & 1.2 & +0.1 & +9.1 & 0.9 & -0.3 \\
\hline Carpet bowls & 0.4 & 0.4 & - & - & 0.4 & - \\
\hline Ice/snow sports & 1.4 & 1.3 & -0.1 & -7.1 & 1.6 & +0.3 \\
\hline Shooting sports & 0.6 & 0.4 & -0.2 & -33.3 & 0.4 & - \\
\hline Scuba diving & 1.1 & 0.5 & -0.6 & -54.5 & 0.5 & - \\
\hline Darts & 0.9 & 0.2 & -0.7 & -77.8 & 0.2 & - \\
\hline Lawn bowls & 2.7 & 1.9 & -0.8 & -29.6 & 2.3 & +0.4 \\
\hline Golf & 9.6 & 8.2 & -1.4 & -14.6 & 8.7 & +0.5 \\
\hline Tenpin bowling & 2.9 & 1.0 & -1.9 & -65.5 & 0.8 & -0.2 \\
\hline Fishing & 5.3 & 2.4 & -2.9 & -54.7 & 2.3 & -0.1 \\
\hline
\end{tabular}


The two ERASS reports continue the use of all these variables except country of birth; in addition they include three additional variables: marital status; existence of dependant children; and level of education. While absolute levels of participation cannot be compared over time because of the changes in survey design, it is possible to compare the ratio of group participation with the average (with some caution, since changing survey design may affect different groups differently). With only two ERASS surveys, it is not possible to examine the three additional variables. But as regards the other variables, it can be said that greater equity was achieved over the period in relation to: women; people aged 65 and over; overseas born. In each case the participation rate for these groups moved closer to the overall average.

\section{Other leisure participation data}

From the point of view of the leisure researcher, the NRPS, with its comprehensive coverage of most aspects of leisure, was ideal, but for its limited sample size. Following the demise of the NRPS, the above discussion has concentrated on the 'sport and physical activities' saga, but what of participation in other aspects of leisure participation during the 1990s and beyond? Brief comments are offered below on surveys of: a. time-use; b. the arts; c. tourism; d. visiting parks; e. children's participation; f. sport spectating; g. exercise; and h. sporting interests and activities (Sweeney Research). Details of the surveys referred to are presented in Table 5.

\section{a. Time-use}

In some other countries, the history of time-use research goes back to the early part of the $20^{\text {th }}$ century (Harvey and Pentland, 1999), but it became a significant focus of international social research with the conduct of the Multinational Comparative Time-Budget Research Project in the 1960s (Szalai 1972) and has developed considerably since (Gershuny 2000). Although the Cities Commission conducted a limited study involving a time-use element in the 1970s (Cities Commission, 1975), it was not intil 1987 that, at the behest of the federal Office of the Status of Women, the ABS began a program of research on time-use with a pilot study conducted in Sydney (ABS, 1988). The ABS conducted the first full-scale national survey of time-use in Australia 1992 and this was replicated in 1997 (ABS, 1994, 1998c). As with the surveys discussed above, there were changes in design between the two time-use surveys, which makes comparison of some leisure activities difficult, but the discipline of 1440 minutes in everyone's day means that comparisons from survey to survey are less affected by vagaries of survey design in time-use studies. While the original intention was to conduct such surveys every five years, the 2002 survey was cancelled, but the latest news from ABS is that another is planned for 2005-06 'if budget and priorities permit' (NCCRS, 2002: 6).

Such surveys cover all aspects of time-use, including all aspects of leisure, and are a key source of information for leisure studies and provide a comprehensive 'snap-shot' picture of participation in leisure, work and other activities on a typical day - usually in one or more seasons of the year. Time-use is generally studied by means of one-day or two-day diaries completed by survey respondents. Thus, in effect, the 'reference period' for the survey is one or two days. This overcomes the problem of recall accuracy involved in surveys which use longer recall periods, and results in more reliable data. 
Table 5. Other Australian national leisure participation and time-budget surveys, 1984-2002

\begin{tabular}{|c|c|c|c|c|c|c|c|c|c|c|c|}
\hline Survey & Year & $\begin{array}{l}\text { Organ- } \\
\text { isation }\end{array}$ & $\begin{array}{l}\text { Survey } \\
\text { type* }\end{array}$ & $\begin{array}{l}\text { Activities } \\
\text { covered }\end{array}$ & $\begin{array}{l}\text { Reference } \\
\text { period }\end{array}$ & $\begin{array}{l}\text { Participation } \\
\text { measure }\end{array}$ & $\begin{array}{l}\text { Seasons } \\
\text { covered } t\end{array}$ & Area covered & Sample Size & $\begin{array}{l}\text { Age- } \\
\text { range }\end{array}$ & Report reference \\
\hline $\begin{array}{l}\text { How Australians Use their } \\
\text { Time }\end{array}$ & $\begin{array}{l}1992 \& \\
1997 \\
\end{array}$ & $\mathrm{ABS}$ & TBS & All time & 1 day & Time spent & Year & Nationwide & 9000 & $15+$ & ABS, 1993, 1998 \\
\hline $\begin{array}{l}\text { Attendance at Cultural } \\
\text { Venues }\end{array}$ & $\begin{array}{l}1991 \\
1995 \\
1999\end{array}$ & $\begin{array}{l}\text { ABS } \\
\text { (MPS) }\end{array}$ & QS & $\begin{array}{l}\text { Selected arts } \\
\text { venues }\end{array}$ & 1 year & $\begin{array}{l}\text { At least one } \\
\text { visit }\end{array}$ & Year & Nationwide & $\begin{array}{l}16,000 \\
26,000 \\
25,200\end{array}$ & $15+$ & ABS 1992; 1995; 1999 \\
\hline Australians and the Arts & 1999 & $\begin{array}{l}\text { Australia } \\
\text { Council }\end{array}$ & QS & $\begin{array}{l}\text { Arts, entertain- } \\
\text { ment, media }\end{array}$ & 2 weeks & At least once & Not specified & Nationwide & 1200 & $15+$ & Saatchi and Saatchi, 1999 \\
\hline $\begin{array}{l}\text { Australian Everyday } \\
\text { Cultures }\end{array}$ & $1994 / 95$ & $\begin{array}{l}\mathrm{ARC} / * * * * \\
* * * *\end{array}$ & QS & $\begin{array}{l}\text { Arts, culture, } \\
\text { sport, tourism }\end{array}$ & $\mathrm{n} / \mathrm{a}$ & Frequency & All & Nationwide & 2756 & $18+$ & Bennett et. al. (1999) \\
\hline National Visitor Survey & Annual & BTR & QS & $\begin{array}{l}\text { Domestic } \\
\text { tourism }\end{array}$ & 2 months & $\begin{array}{l}\text { Overnight stay } \\
\text { at least } 40 \mathrm{~km} \\
\text { from home }\end{array}$ & All year & Nationwide & 80000 & $15+$ & BTR, Annual \\
\hline Visits to National Parks & $1996-07$ & $\begin{array}{l}\mathrm{ABS} \\
(\mathrm{PSM})\end{array}$ & QS & National Parks & Year & At least once & All year & Nationwide & 13000 & $18+$ & ABS, $1997 \mathrm{c}$ \\
\hline $\begin{array}{l}\text { Children's Participation in } \\
\text { Cultural and Leisure } \\
\text { Activities }\end{array}$ & 2000 & $\begin{array}{l}\text { ABS } \\
\text { (MPS) }\end{array}$ & QS & $\begin{array}{l}\text { Organised sport } \\
\text { Selected leisure } \\
\text { Computers } \\
\end{array}$ & Variable & Variable & Variable & Nationwide & 9700 & $5-15$ & ABS, 2001 \\
\hline Sports Attendance & $\begin{array}{l}1995 \\
1999 \\
\end{array}$ & $\begin{array}{l}\text { ABS } \\
\text { (MPS) } \\
\end{array}$ & QS & Sport spectating & 1 year & At least once & All year & Nationwide & 25200 & $15+$ & ABS, 1995b, 1999c \\
\hline $\begin{array}{l}\text { Physical Activity Levels } \\
\text { of Australians }\end{array}$ & $\begin{array}{l}1984 \\
1985 \\
1985 \\
1986 \\
1986 \\
1987 \\
\end{array}$ & DASETT & QS & $\begin{array}{l}\text { 'Physical } \\
\text { activity' + partn } \\
\text { in } 17 \text { listed } \\
\text { activities }\end{array}$ & 2 weeks & $\begin{array}{l}\text { Frequency in } 2 \\
\text { weeks }\end{array}$ & $\begin{array}{l}\text { Winter } \\
\text { Summer } \\
\text { Summer } \\
\text { Summer } \\
\text { Winter } \\
\text { Summer } \\
\end{array}$ & Nationwide & $\begin{array}{l}3500 \\
3480 \\
3390 \\
3360 \\
3700 \\
3590 \\
\end{array}$ & $14+$ & DASETT, 1988a \\
\hline $\begin{array}{l}\text { Physical Activity Levels } \\
\text { of Australians }\end{array}$ & $\begin{array}{l}1997 \\
1999 \\
2000 \\
\end{array}$ & $\begin{array}{l}\text { Active } \\
\text { Australia }\end{array}$ & QS & Physical activity & $\begin{array}{l}1 \text { week }+ \\
\text { weekly in last } \\
6 \text { months }\end{array}$ & $\begin{array}{l}\text { Frequency + } \\
\text { intensity }\end{array}$ & $\begin{array}{l}\text { Mid-winter - } \\
\text { early Summer }\end{array}$ & Nationwide & $\begin{array}{l}4800 \\
4800 \\
4800 \\
\end{array}$ & $18-75$ & $\begin{array}{l}\text { Bauman, 1998; Armstrong } \\
\text { et al., 2000; Bauman et al. } \\
2001\end{array}$ \\
\hline Sweeney Sports Report & $\begin{array}{l}\text { 1986-02, } \\
\text { annual }\end{array}$ & $\begin{array}{l}\text { Sweeney } \\
\text { Research }\end{array}$ & QS & Sport & Not specified & - & - & $\begin{array}{l}\text { Mainland } \\
\text { capitals }\end{array}$ & 1500 & $16-65$ & $\begin{array}{l}\text { Sweeney Sports Report } \\
\text { (Annual) }\end{array}$ \\
\hline
\end{tabular}

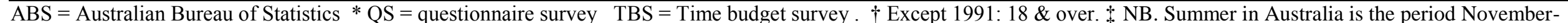
February; Winter is the period May-August. BTR = Bureau of Tourism Research. PSM = ABS Population Survey Monitor. MPS = ABS Monthly Population Survey. 
Time-use surveys do, however, play a different role to the sorts of leisure survey discussed above since, except for activities typically engaged in on a frequent basis - daily, or at least several times a week - the sub-samples of participants in individual activities tend to be very small. For example, in the case of the popular activity of golf, $8.2 \%$ of the adult population play at least once a year and the median frequency of participation is 25 times a year (Dale and Ford, 2002: 9), so a conventional questionnaire survey with a sample of, say, 5000 respondents, would produce a sub-sample of golfers of over 400, facilitating detailed analysis. But on an average single day, the proportion of the population playing golf will be less than $1 \%$, so a time-use survey might produce a sub-sample of less than 50. For a less popular sport, such as rugby union, or an activity engaged in infrequently, such as visiting a museum, the proportion participating in an average day might be less than $0.1 \%$. Thus very large sample sizes are necessary to produce suitable sub-samples of individual activities for detailed study. Thus the conventional questionnaire survey is a more cost-effective method of gathering data on most individual leisure activities.

At the other extreme, as discussed above, it is arguable that the one year reference period used in many surveys is too long, introducing problems of accuracy of recall and perhaps including too many very occasional participants. The NRPS of the 1980s, which, as we have seen, used a one week reference period (and, on one occasion, also a one month period), can be seen as a compromise between the two extremes, as can the British General Household Survey, which uses a four-week reference period (Gratton, 1996), but such surveys must be repeated at different time of the year to capture seasonal variation.

\section{b. The arts}

During the 1980s the arts management community, including the Australia Council, depended on the NRPS for data on participation in the arts (see Australia Council 1992). In 1991, however, a new ABS survey was launched, Attendance at Selected Cultural Venues, and was repeated in 1995 and 1999 (ABS 1992; 1995; 1999b). Once again, we see changes in survey design, with the 1991 survey including persons aged 18 and over and the 1995 survey being extended to those aged 15 and over, and the list of venues changed. No comparison is therefore given between the two surveys in the 1995 report. In the 1999 report, however, there were minimal changes, and comparisons with the previous survey were given. The survey was repeated in 2002 (NCCRS 2002: 4), but the results are not available at the time of writing.

The Attendance at Selected Cultural Venues survey is clearly of value for much of the arts industry, indeed, similar questions related to other types of leisure venue, such as national parks, beaches and swimming pools, had been included in the NRPS, but not in subsequent non-arts surveys. However, the survey does not encompass all forms of arts participation and this was remedied by the Australia Council in 1999 when it commissioned Saatchi and Saatchi (1999) to conduct the Australians and the Arts survey. This survey was based on a relatively small sample (1200) and used a unique reference period (two weeks), making comparisons with other survey data impossible. There has been no repeat of the survey.

A one-off survey of arts, culture and leisure participation, 'Australian Everyday Cultures', was conducted in 1994/95 by Tony Bennett and his associates then at the Key centre for Cultural Policy at Griffith University, involving a nationwide sample of 2700 adults. While publicly funded by the Australian Research Council, it is notable that this is the only survey covered in this revise which was instigated by academics. The range of activities covered is wide, including participation in the arts, sport and tourism and detailed consideration of cultural tastes and preferences. Equity/class and access issues are explored in some detail. The 
participation data are, however, of limited use because of the use of imprecise measures of participation, such as 'often', 'sometimes', 'hardly ever'.

\section{c. Tourism}

The federal/state government partnership model, as seen in relation to the conduct of sport and physical activity surveys from the 1990s, is of much longer standing in the tourism area. A separate body, the Bureau of Tourism Research has been in existence from the 1980s to gather participation data, for both domestic and inbound tourism. As regards domestic tourism, first the Domestic Tourism Monitor, and more recently the National Visitor Survey, have been conducted annually since the 1980s, with sample sizes of the order of 80,000 (see Table 5). The large sample size makes it possible to provide data on trips to and from a large number of regions below the level of the state - a level of analysis which is not possible with the limited sample sizes used in most of the other surveys discussed.

The tourism industry is interested in the number of trips to a destination, including seasonal variations. This is achieved by conducting interviews throughout the year and gathering data on respondents' trips over the two months prior to interview. This approach, however, cannot produce an estimate of the proportions of the population which takes or does not take a holiday away from home in a given year. This obvious equity-related statistic is, therefore, not collected for tourism.

Consideration of tourism prompts the observation that other forms of leisure survey generally fail to ask whether recorded activities take place while the respondent was on holiday - an omission which raises a question as to the appropriateness of some of the data for local leisure service planning.

\section{d. Visiting parks}

National parks are a major public sector responsibility, but the collection of data on levels of visitation is spasmodic. It might be speculated that this is due to responsibility lying with ministers and departments for the environment, who have not been centrally involved with the National Leisure and Culture Statistical Framework as have ministers and departments for culture and for sport and recreation. It might also be speculated that ministers and departments of the environment are content with the site-based data on attendances collected by individual national parks agencies, despite the fact that such data are very patchy, often depend on 'guesstimates' in relation to parks which do not charge entrance fees, and do not provide socio-economic data and equity of access. Questions on national park visiting were included in the NRPS and questions were included in the 1996-97 ABS Population Survey Monitor, the survey vehicle used to gather the data on sport and physical activities, but this has not been repeated, so no trend data are available.

Urban parks are an even more significant resource in terms of public expenditure and day-to-day impact on people's lives. Again, data were collected in the NRPS, but none have been collected on a national basis since 1991 .

It is notable that the arts-orientated ABS surveys of Attendance at Selected Cultural Venues, discussed above, include not just arts venues such as theatres and art galleries, but outdoor 'cultural heritage' venues such as zoos and botanic gardens. It seems a missed opportunity that other types of urban park and other types of natural heritage are not included - or, for that matter, other types of leisure venue, such as swimming pools, pubs and clubs.

\section{e. Children}

All the surveys discussed above include adults only, sometimes including people aged 15 and over and sometimes those aged 18 and over. The initial ABS surveys of sport and physical 
activity included data on children aged 5-14, but these were collected from an adult in the sampled households and covered only 'organised' activities. It is clear from the results that children are likely to make up a significant proportion of participants in the organised form of some activities, such as swimming and basketball, but, because of the way the data were collected, the adult and children's data could not be aggregated. The questions were dropped from the 1997-98 survey onwards.

In the year 2000 the ABS replicated the children's part of its 1995-96 survey, using the larger Monthly Population Survey, again with questions on children's participation addressed to a single adult in the sample households. On this occasion a separate report was published (ABS 2001). Participation was, however, measured differently for different groups of activities. Organised sport participation referred to 'out of school hours in the last year'; participation in other leisure activities referred to 'outside school hours in the previous two school weeks'; and participation in computer activities referred to 'during or outside school hours in the last 12 months'. The groups of activities are not comparable with any grouping used for adult leisure participation surveys, with the exception of 'organised sport' played in the year prior to interview. However, in this case, if a child played 'more than three organised sports outside of school hours, respondents were asked to select the three sports that the child played most frequently'. It is not known what effect this restriction might have had on the results but, even so, children's overall participation rate, at $66 \%$, was higher than that recorded for adults. For a number of individual organised activities, children's participation levels are greater than those of adults by a factor of two or three, thus the adult participation rates are highly misleading as an indicator of the overall size of the playing population for activities such as athletics, Australian rules football, dancing, gymnastics, rugby league, soccer and swimming.

A number of equity variables are presented, namely: age, gender, birthplace, state/territory, region (capital city/other), family type (one-parent, other), birthplace of parents, and employment status of parents.

\section{f. Sport spectating}

The NRPS included sport spectating among its 90 activities, but in the subsequent ABS/PSM and ERASS surveys it was ignored. The ABS sought to fill the gap with surveys of Sport Attendance conducted in 1995 and 1999. A change in design between the 1995 and 1999 surveys in this instances was brought about by an apparent under-counting of motor-sport attendance in 1995, and there was a change from telephone to face-to-face interviewing, necessitating 'some wording changes to the questions in the 1999 survey as prompt cards could not be used'. There was, however, a five-year gap between surveys, a period during which it is reasonable to consider social change. It is all the more notable then, that the participation rate (excluding motor-sport) for 1999 , at $43.1 \%$, was only $0.1 \%$ different from the rate recorded in 1995.

\section{g. Exercise}

If information is required on people's levels of physical exercise in regard to health benefits, surveys which ask about participation in a sport or physical recreation activity 'at least once in the previous year' are of limited use. Exercise needs to be taken on a regular basis for more than a specified amount of time and with a specified level of intensity to provide health benefits. Separate surveys on exercise, gathering this more detailed information, have therefore been conducted over the years. Thus, during the 1980s, the government department responsible for the NRPS also conducted the Physical Activity Levels of Australians surveys on six occasions, each with a sample size of 3500. The summary report suggests that this 
series remained methodologically stable, so that comparisons could be made from one survey to the next (DASETT, 1988a). However, of the six surveys, three took place in winter and three in summer, so comparisons could only be made among the three winter surveys and among the three summer surveys. The winter surveys suggested that the overall level of exercise was static, while the summer surveys suggested a slow increase. Only a quarter of respondents had a level of exercise participation high enough to improve fitness. Equity variables included were: age, sex, education level, income, occupation, work status and lifecycle stage. Unlike the NRPS reports, the summary report does discuss the policy implications of the findings.

Under the auspices of the national 'Active Australia' campaign, surveys of the Physical Activity Levels of Australians were conducted in 1997, 1999 and 2000). The published reports make no reference to the earlier surveys (Bauman 1998; Armstrong, Bauman and Davies, 2000; Bauman, Ford and Armstrong, 2001); indeed, neither does the 'Active Australia' policy document (Commonwealth Department of Health and Family Services, 1998). Compared with the 1980s surveys, the age-range covered is different (18+ compared with 14+) and participation measures are different. The latter are quite unique, referring to participation in the previous week and 'weekly levels of activity in the last six months'. Different criteria are also used to assess the 'sufficient physical activity to generate health benefits'. The three surveys used a common methodology, so trends over three years 1997-2000 can be measured. In the published reports the equity variables included are age, gender, education and state/territory of residence.

Both the 1980s surveys and the recent surveys provide a classic example of policy monitoring. The simple aim of the Active Australia campaign is to increase the proportion of the population undertaking a specified level of physical activity in order to produce health benefits. The surveys are clearly focussed on providing outcome data to monitor the impact of the campaign. What is more remarkable, however, is that the published reports openly demonstrate failure. The three recent surveys show the level of 'sufficient activity' declining from $51 \%$ to $46 \%$ using one measure and from $62 \%$ to $57 \%$ using another.

These studies claim to be concerned with physical exercise, which does not take place exclusively during leisure time. The 1980s surveys, however, concentrated on leisure-time activity only. The scope of the 1997-99 surveys was widened to include 'household chores' and 'gardening and yard work', but neither study included job-related activity.

\section{h. Sporting interests and activities (Sweeney Research)}

A Melbourne-based market research company, Sweeney Research, has conducted annual surveys on 'sporting interests and activities' since 1986. The surveys are conducted with commercial clients in mind and are funded from the sale of results to subscribers. The reports are therefore expensive and are not generally available in the public domain. ${ }^{8}$ The participation question used by Sweeney Research asks which of 56 named sports respondents are 'interested in' and whether they actually participate, attend as a spectator, watch it on TV, listen on radio or read about it in newspapers. This is information which is of particular interest to advertisers and marketers. The participation data are, however, not related to any time period, so different respondents may interpret the term 'participate' differently. As a discussion paper by the ABS unit, the National Centre for Culture and Recreation Statistics, (NCCRS, 2001; Marriott, 2001) indicates, the result is a range of participation rates which are considerably higher than ABS rates - as much as $300 \%$ higher for some activities. 


\section{Identifying the problems}

Three major problems can be identified from the above review and discussion of the collection of leisure participation data in Australia: 1. links with policy; 2. lack of consistency; and 3. fragmentation.

\section{Links with policy}

Links between public policy and the conduct of surveys are generally clear in the initial stages when survey programs are established. But the relationships between the results and the process of monitoring policy outcomes are, with few exceptions, far from clear. This is true not only in regard to measurement of overall participation levels, but particularly in relation to assessment of equity of outcomes. Of course such analyses may be available in government departments in unpublished internal documents. In other policy areas, such as health or education, policy outcomes - or lack of outcomes - are a matter for public debate. It is not clear why leisure policy should be an exception to this rule. The nearest approximation is debate on the winning of international sporting medals, where outcomes (medals won) are frequently related to inputs (money and organisation) (Hogan and Norton, 2000). Discussion of the problem of increasing child and adult obesity is seen as a health problem and related to the question of exercise, but is rarely linked directly to leisure policy, although clearly declining levels of exercise in the community, as indicated above, suggests policy failure. Despite scores of surveys conducted at a cost of millions of dollars, ${ }^{10}$ it is not clear that the public sector in Australia has a great deal to show in terms of understanding the relationship between leisure policy measures and participation outcomes.

\section{Lack of consistency}

The problem of lack of consistency refers to the numerous changes made to survey designs, such that no one survey vehicle has remained the same for more than two or three outings. The result is that no data exist on trends in leisure participation in Australia over time.

In this regard the tourism sector has a better track record than most of the other sectors reviewed, but even there, changes have bedevilled the problem of monitoring change. Again, the area which has come close to achieving some sort of trend measurement is physical exercise, but the maximum number of comparable surveys conducted so far is three surveys over three years. There is also a commitment to repeat the ERASS survey for three years. But experience from Australia and overseas (Cushman et al., 1996) suggests that leisure participation is volatile in the short-term, affected by such factors as weather, events, fashion and economic fluctuations. It is arguable that surveys over at least a decade are necessary to identify serious trends. Rather than conducting annual surveys in two or three consecutive years, the departments involved might be better advised to spend their resources on the same number of surveys but conducted every three years, resulting in coverage of at least a decade.

The tendency for new personnel in 'client' government departments or in statistical agencies to want to innovate and put their own stamp on a survey vehicle has been noted by Jiri Zuzanek in the Canadian context, but, as he expresses it: 'The virtues expected of large scale statistical surveys are not necessarily novelty and experimentation, but rather acrosssurvey and across-time consistency' (Zuzanek, 1996: 71). Apart from the loss of trend data for policy analysis and academic research, the cost of frequent redesigning of already expensive survey vehicles must be substantial.

Reference to the international context draws attention to the fact that Australia is not unique in its inconsistent and fragmented approach to leisure participation data collection. The consequence is that, with the exception of time-use data (Gershuny, 1999: 270-88) and some 
efforts in realtion to sport in Europe (Gratton, 1999), as Cushman at al. (1996) point out, it is virtually impossible to make international comparisons of levels and patterns of leisure participation.

\section{Fragmentation}

Fragmentation of data collection into various sectors of leisure results in data on different sectors being collected in different ways at different times, so that aggregation and comparison are virtually impossible. Further, data on participation in many activities are not collected at all because they do not fall within the portfolio of the federal or the state government ministers and departments who are generally the primary 'clients' for the data collected. Examples include activities such as visiting urban parks and beaches, home-based leisure, and social activities, such as going to clubs or pubs. Even where activities do not relate to publicly provided facilities and resources, it is arguable that information about them wouldcontribute to an understanding of leisure and lifestyles as a whole, and the competition for people's leisure time and the 'leisure dollar'.

In the academic field of leisure studies, and to some extent in the private sector, considering leisure as a single, broad, though multi-faceted, concept has long been accepted as appropriate (see Veal and Lynch, 2001: 18-26; Veal, 1992), but, although there are occasional flourishes of ministerial rhetoric and frequent use of the term 'and recreation' in ministerial and departmental titles, suggesting a broad approach, the idea of leisure, as a comprehensive phenomenon, has never found favour in government. In Australia, the nearest government has come to recognising the scope of leisure has been the establishment within the Australian Bureau of Statistics of the National Centre for Culture and Recreation Statistics, which engages in a wide range of valuable data collection in the field, but has not been given the job of gathering a comprehensive, consistent picture of leisure participation to monitor trends and inform policy. Why governments - in Australia and elsewhere - tend to have separate ministers, departments and policies for many of the various components of leisure (sport, outdoor recreation, the arts, culture, entertainment and broadcasting, tourism, children's play) but no minister, department or policies for leisure as a whole is an intriguing question but one which it has not been possible to pursue in the limited context of this paper.

\section{Conclusions}

The above discussion draws attention to the failure of government-sponsored data collection to fulfil its public purposes and functions. The discussion is couched in methodological and policy-related terms, but many of the problems and issues identified are also relevant to theoretical issues. Many academic discussions of leisure which draw upon empirical data have the same concerns and needs as policy-makers and policy-evaluators: that is, they are concerned with identifying, explaining and predicting trends in social behaviour and they are concerned with differences in behaviour among social groups, and even with the effects of government policy. Academics are of course, often concerned with much more than just participation outcomes; they are concerned with motivation and preferences, choice, substitution and the quality of experience. But basic factual data on patterns of participation in the community provide an essential backdrop and major survey vehicles can often also be used to gather information on preferences and motivation (Cushman and Veal, 1993). Thus if the policy-makers who drive the official leisure participation survey process could solve the above problems of policy-linkage, fragmentation and consistency, this would not only benefit the policy process but would also substantially serve the needs of academic research. 
There is clearly a need for a 'whole of government' approach to solve the problem of data collection on leisure participation in Australia.

\section{Notes}

1. Since the NSW population increases by some 60,000 a year, barely achieving the department's target of an additional 50,000 participants would involve a gradual decline in the participation rate. In its 2001-2002 Annual Report (NSW Dept of Sport and Recreation, 2003b) the department cites data from the 2001 ERASS survey (discussed later in the paper) as an 'outcome'. This shows 3.971 million participants in NSW. The 2002 survey, however, indicates that this figure has declined by 56,000 to 3.915 million. The 2002-2003 Annual Report will therefore make interesting reading.

2. The final NRPS, conducted in Summer 1991, also included data on participation in the previous month (Darcy, 1993). In addition to the basic participation question, the survey also asked about attendance at selected facilities and asked about desires for increased participation and reasons for non-participation.

3. The National Sport and Recreation Industry Statistical Framework complemented the National Culture-Leisure Industry Statistical Framework, which was developed by the Culture Ministers Council in the 1980s, following UNESCO guidelines. More recently, these two frameworks have been brought together as the Australian Culture and Leisure Classifications (ACLC) (ABS, 2001). The latter includes and 'Industry Classification', a 'Product Classificatio' and an 'Occupation Classification', but no 'Activity Classification. In the ACLC report, an appendix listing relevant activities used in the ABS 1997 Time Use survey. However, in this classification activities in the sporting area are mainly aggregated - for example 'organised sport', 'informal sport' - rather than individually listed.

4. More than 42 activities were included in the survey, but details of those with less than $0.3 \%$ participation were not reported for statistical reasons.

5. In fact, the NRPS reports do not give an overall figure for sport participation, but at the end of the listing of participation levels in individual sporting activities for males and females, figures are given for 'none of the above'. For the summer 1991 survey, this was, for organised sport, males: 28\% ; females: $23 \%$ (mean: $25 \%$ ); and for informal sport, males: $28 \%$; females: $26 \%$ (mean 27\%); implying overall sport participation figures of $75 \%$ for organised sport and $77 \%$ for informal sport (DASETT, 1991: 14-17).

6. The 2001 ERASS report carried the Australian Sports Commission (ASC) logo and was authored by two ASC staff. It is indicated in the ministerial foreword and the introduction that the survey is 'the work of' and is 'funded by' the Australian Sports Commission and the State/Territory Departments of Sport and Recreation. The 2002 report, however, has no named authors and the ASC is not mentioned. A 'librarian's nightmare', the report does not clearly indicate author, publisher, date of publication or ISBN. The front cover includes all the state/territory department logos and carried the statement: 'Funded by the State/Territory Departments of Sport and Recreation through the Standing Committee on Recreation and Sport (SCORS)'. There is an element of deja $v u$ in the study, in that the company engaged to conduct the surveys was ACNielsen, the company which took over AGB:McNair, which had conducted the NRPS. A September note from the ABS National Centre for Culture and Recreation Statistics (2002: 5) indicates that the ABS has collected sport and physical recreation data again in its 2002 General Social Survey, the results to be published in 2003.

7. The Olympic activity of competitive walking is included in Athletics.

8. Information for this discussion draws largely on the National Centre for Culture and Recreation Statistics (2001) paper comparing Sweeney and ABS data.

9. In fact the NRPS of the 1980s gathered information of activities respondents wanted to engage in and were unable to and factors preventing participation.

10. No research has been done on the aggregate costs of the surveys conducted, but the total number of interviews conducted in the surveys examined is:

$$
\begin{array}{lc}
\text { NRPS } & 14,200 \\
\text { ABS/PMS } & 85,500 \\
\text { ERASS } & 27,200
\end{array}
$$


Other $\quad 150,700$ (approx., excl. Sweeney, and National Visitor Survey)

Total 277,600

Bearing in mind that some of the surveys utilised existing 'omnibus' surveys, even allowing a modest $\mathrm{A} \$ 20$ per interview, at today's prices the cost is of the order of $\$ 5.5$ million.

\section{Acknowledgements}

I would like to thank the referees for helpful comments on the paper and Dr Ken Marriott for commenting on an early draft of the paper. AJV

\section{References}

Armstrong, T., Bauman, A. and Davies, J. (2000) Physical Activity Patterns of Australian Adults: Results of the 1999 National Physical Activity Survey. Canberra: Australian Institute of Health and Welfare. Available at: www.activeaustralia.org/facts/index.htm - accessed, Aug. 2003.

Auld, C. (1989) The relationship of recreation to nine selected occupation categories. In Department of the Arts, Sport, the Environment, Tourism and Territories, Ideas for Australian Recreation: Comments on the Recreation Participation Surveys. Canberra: AGPS, 86-102.

Australia Council (1992) The Arts: Some Australian Data. Fourth edn, Redfern, Australia Council. Australian Bureau of Statistics (ABS) (1978) General Social Survey: Leisure Activities Away from Home, (Cat. No. 4104.0). Canberra: ABS.

Australian Bureau of Statistics (ABS) (1988) Information Paper: Time Use Pilot Survey -Sydney, May-June, 1987, (Cat. No. 4111.1). Sydney: ABS.

Australian Bureau of Statistics (ABS) (1992) Attendance at Selected Cultural venues, Australia, June 1991, (Cat. No. 4114.0). ABS, Canberra.

Australian Bureau of Statistics (ABS) (1994) How Australians Use Their Time, (Cat. No. 4153.0). ABS, Canberra.

Australian Bureau of Statistics (ABS) (1995a) Attendance at Selected Cultural Venues, Australia, March 1995, (Cat. No. 4114.0). ABS, Canberra.

Australian Bureau of Statistics (ABS) (1995b) Sports Attendance, Australia, March 1995, (Cat. No. 4174.0). Canberra: ABS.

Australian Bureau of Statistics (ABS) (1997a) Participation in Sport and Physical Activities, Australia, 1995-96, (Cat. No. 4177.0). ABS, Canberra.

Australian Bureau of Statistics (ABS) (1997b) Culture and Recreation - National Parks. Adelaide: National Centre for Culture and Recreation Statistics, ABS, at: www.abs.gov.au/ausstats (accessed August 2001)

Australian Bureau of Statistics (ABS) (1998a) Participation in Sport and Physical Activities, Australia, 1996-97, (Cat. No. 4177.0). ABS, Canberra.

Australian Bureau of Statistics (ABS) (1998b) Participation in Sport and Physical Activities, Australia, 1997-98, (Cat. No. 4177.0). ABS, Canberra.

Australian Bureau of Statistics (ABS) (1998c) How Australians Use Their Time, (Cat. No. 4153.0). ABS, Canberra.

Australian Bureau of Statistics (ABS) (1999a) Participation in Sport and Physical Activities, Australia, 1998-99, (Cat. No. 4177.0). ABS, Canberra.

Australian Bureau of Statistics (ABS) (1999b) Attendance at Selected Cultural Venues, Australia, March 1995, (Cat. No. 4114.0). ABS, Canberra.

Australian Bureau of Statistics (ABS) (1999c) Sports Attendance, Australia, April 1999, (Cat. No. 4174.0). Canberra: ABS.

Australian Bureau of Statistics (ABS) (2000a) Participation in Sport and Physical Activities, Australia, 1999-2000, (Cat. No. 4177.0). ABS, Canberra.

Australian Bureau of Statistics (ABS) (2000b) Children's Participation in Cultural and Leisure Activities, (Cat. No. 4901.0). Canberra, ABS.

Australian Bureau of Statistics (ABS) (2002) ABS Directions and Data Collections in the Area of Sport and Recreation. Canberra, ABS (available at: www.abs.gove.au). 
Bachman, J. G. and O'Malley, P. M. (1981) When four months equal a year: inconsistencies in student reports of drug use. Public Opinion Quarterly, 45(4), 536-48.

Bauman, A. (1998) Physical Activity Levels of Australians: Results of the Active Australia Baseline Survey - November 1997. Canberra: Australian Sports Commission/Active Australia. Available at: www.activeaustralia.org/facts/index.htm - accessed Aug. 2003.

Bauman, A., Ford, I. and Armstrong, T. (2001) Trends in Population Levels of Reported Physical Activity in Australia, 1997, 1999 and 2000. Canberra: Australian Sports Commission/Active Australia. Available at: www.activeaustralia.org/facts/index.htm - accessed Aug. 2003.

Bennett, T., Emmison, M. and Frow, J. (1999) Accounting for Tastes: Australian Everyday Culture. Cambridge, Cambridge University Press.

Brown, J. (1985) Towards a Commonwealth Policy for Recreation, Canberra: A.G.P.S.

Bureau of Tourism Research (Annual) National Visitor Survey. Canberra: BTR.

Chase, D. R. and Godbey, G. C. (1983) The accuracy of self-reported participation rates. Leisure Studies, 2 (2), 231-6.

Chase, D. and Harada, M. (1984) Response error in self-reported recreation participation. Journal of Leisure Research, 16 (4), 322-9.

Cities Commission (1975) Australians' Use of Time. Melbourne: Cities Commission.

Commonwealth Department of Health and Family Services (1998) Active Australia. Canberra: DHFS.

Commonwealth of Australia (1994) Creative Nation: Commonwealth Cultural Policy, October 1994. Canberra: Department of Communication and the Arts.

Commonwealth of Australia (2001) Backing Australia's Sporting Ability: A More Active Australia. Canberra, Department of Sport and Tourism.

Corporate Concern (1994a) The National Sport and Recreation Industry Statistical Framework. First Draft, Prepared for the Sport and Recreation Ministers Council, Adelaide: Corporate Concern.

Corporate Concern (1994b) Available Data and Sources for the Sport and Recreation Industry. Draft, Prepared for the Sport and Recreation Ministers Council, Adelaide: Corporate Concern.

Cushman, G. and Veal, A. J. 1993, The new generation of leisure surveys - implications for research on everyday life. Leisure and Society, 16(1), 211-220.

Cushman, G., Veal, A. J., and Zuzanek, J. (eds) (1996) World Leisure Participation: Free Time in the Global Village, Wallingford, Oxon, UK, CAB International.

Dale, T. and Ford, I. (2002) Participation in Exercise, Recreation and Sport, 2001, Canberra: Australian Sports Commission (available at: www.ausport.gov.au).

Darcy, S. (1993) Leisure participation in Australia: the monthly data. Australian Journal of Leisure and Recreation, 4(1), 26-32.

Darcy, S. and Veal, A. J. (1996) Australia. In Cushman, G., Veal, A. J., and Zuzanek, J. (eds) World Leisure Participation: Free Time in the Global Village, Wallingford, Oxon, UK, CAB International, 17-34.

Department of the Arts, Sport, the Environment, Tourism and Territories (1988) Recreation Participation Survey: October/November 1987. Canberra: DASETT.

Department of the Arts, Sport, the Environment, Tourism and Territories (1991) Recreation Participation Survey: February 1991. Canberra: DASETT.S.

Department of Sport, Recreation and Tourism (1986) Recreation Participation Survey: April/May 1985. Canberra: DSRT.

Department of Sport, Recreation and Tourism (1986a) Recreation Participation Survey: Oct/Nov 1985. Canberra: DSRT.

Department of Sport, Recreation and Tourism (1986b) Recreation Participation Survey: February, 1986. Canberra: DSRT.

Department of Sport, Recreation and Tourism (1986c) Recreation Participation Survey: May, 1986. Canberra: DSRT.

Department of Sport, Recreation and Tourism (1986d) Recreation Participation Survey: July, 1986. Canberra: DSRT.

Gershuny, J. (2000) Changing Times: Work and Leisure in Postindustrial Society. Oxford University Press, Oxford. 
Gratton, C. (1996) Great Britain. In Cushman, G., Veal, A. J., and Zuzanek, J. (eds) World Leisure Participation: Free Time in the Global Village, Wallingford, Oxon, UK, CAB International, pp. 113-30.

Gratton, C. (1999) COMPASS 1999: Sports Participation in Europe. London, UK Sport.

Harvey, A. S. and Pentland, W. (1999) Time use research. In W. E. Pentland, A. S. Harvey, M. P. Lawton and M. A. McColl (eds) Time Use Research in the Social Sciences. New York: Klewer Academic/Plenum, 3-18.

Hogan, K. and Norton, K. (2000) The 'price' of Olympic gold. Journal of Science and Medicine in Sport , 3(2): 203-218.

Houlihan, B. (1997) Sport, Policy and Politics: A Comparative Analysis. London, Routledge.

Leigh, A. and Wolfers, J. (2003) Policy improves by putting rhetoric on trial. Sydney Morning Herald, 5 March, p. 15.

Liberal/National Coalition (1988) A Winning Edge. Canberra: Liberal/National Coalition, Available at: www.liberal.org.au/archive/election98 (Accessed Sept 2000).

Liberal/National Party Coalition (2001) Arts for All. Melbourne: Liberal/National Party Coalition. Available at: www.liberal.org.au/archive/2001\%20election/policy/arts.pdf.

Lynch, R. and Veal, A. J. (1996) Australian Leisure. Melbourne, Longman Australia.

Marriott, K. (2001) Open to question: why the ABS is questioning Sweeney Sports' research findings. Australasian Leisure Management, No. 29, Oct./Nov., p. 20.

National Centre for Culture and Recreation Statistics (NCCRS) (2001) Sport Data on Participation and Attendance: How do Results from the Australian Bureau of Statistics and Sweeney Research Compare? Adelaide: NCCRS, Australian Bureau of Statistics.

National Centre for Culture and Recreation Statistics (NCCRS) (2002) ABS Culture, Sport and Recreation Statistics. Adelaide: ABS (accessed via www.abs.gov.au)

New South Wales Department of Sport and Recreation (2003a) Corporate Plan 2003-2007. Sydney, NSW Department of Sport and Recreation, available at: www.dsr.nsw.gov.au (accessed Oct. 2003).

New South Wales Department of Sport and Recreation (2003b) Annual Report 2001-2002. Sydney, NSW Department of Sport and Recreation, available at: www.dsr.nsw.gov.au (accessed Oct. 2003).

Rogers, L. (1989) Recreation and the impact of education. In Department of the Arts, Sport, the Environment, Tourism and Territories Ideas for Australian Recreation: Comments on the Recreation Participation Surveys. Canberra: AGPS, 79-85.

Saatchi and Saatchi (1999) Australians and the Arts. Sydney, Australia Council (available at: www.ozco.gov.au).

Standing Committee on Recreation and Sport (2003) Participation in Exercise, Recreation and Sport 2002. Canberra, Australian Sports Commission, available at: www.ausport.gov.au info/ statistics.htm

Sweeney Research (Annual) Sweeney Sports Report. Melbourne: Sweeney Research (see: (www. sweeneyresearch.com.au/)

Szalai, A. (ed.) (1972) The Use of Time: Daily Activities of Urban and Suburban Populations in Twelve Countries. Mouton, The Hague.

Veal, A. J. 1992, Definitions of leisure and recreation. Australian Journal of Leisure and Recreation, 2(4), 44-49, 52.

Veal, A. J. (1993a) Leisure participation surveys in Australia. ANZALS Leisure Research Series, 1, 197-210.

Veal, A. J. (1993b) Leisure participation in Australia: 1985-91: a note on the data. Australian Journal of Leisure and Recreation, 3(1), 37-46.

Veal, A. J. (2002) Leisure and Tourism Policy and Planning. Wallingford, Oxon, UK, CABI Publishing.

Veal, A. J. and Lynch, R. (2001) Australian Leisure, $2^{\text {nd }}$ edn. Sydney, Longman.

Zuzanek, J. (1996) Canada. In Cushman, G., Veal, A. J., and Zuzanek, J. (eds) World Leisure Participation: Free Time in the Global Village, Wallingford, Oxon, UK, CAB International, 35-76. 
Figure 1. Participation in organised and non-organised sport and physical activities, Australia, 1991-2002
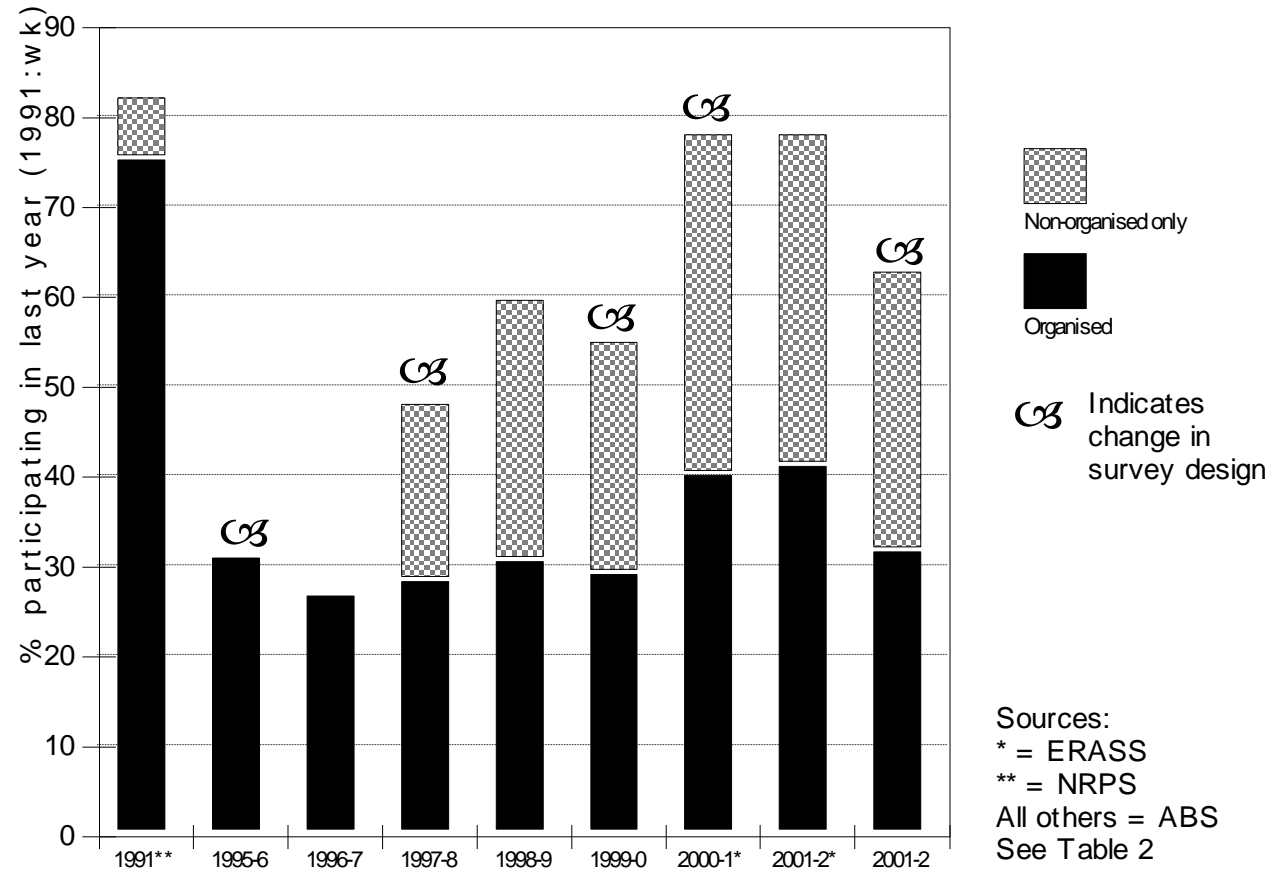

Sources:

* $=$ ERASS

$* *=$ NRPS

All others $=$ ABS

See Table 2 